\title{
Malleable disc base for direct infiltration measurements using the tension infiltrometry
} technique

\author{
David Moret-Fernández ${ }^{*}$, Nuria Blanco, Victor Martínez-Chueca and Ana Bielsa \\ ${ }^{a}$ Departamento de Suelo y Agua Estación Experimental de Aula Dei Consejo Superior de \\ Investigaciones Científicas (CSIC). PO Box 202, 50080, Zaragoza, Spain. \\ * Corresponding author. \\ Telf: +34976716140 \\ Fax: +34976716145 \\ E-mail address: david@eead.csic.es
}




\begin{abstract}
The correct use of the tension disc infiltrometer requires the membrane of the disc base to be completely in contact with the soil surface. To achieve this contact, a thick layer of sand is commonly placed between the soil surface and the disc base. This paper presents an alternative disc $\left(\mathrm{M}_{\mathrm{DB}}\right)$, which, by incorporating a malleable membrane, allows direct infiltration measurements without using a contact sand layer. Infiltration curves obtained with this new design in a soil under three different tillage management treatments were compared to the corresponding curves obtained with a conventional disc $\left(\mathrm{C}_{\mathrm{DB}}\right)$ that uses a contact sand layer. The cumulative infiltration curves measured with $\mathrm{C}_{\mathrm{DB}}$ were analysed by the differentiated linearization (DL) method, and the corresponding curves obtained with $\mathrm{M}_{\mathrm{DB}}$ were analysed using both the DL and the cumulative linearization (CL) models. The values of hydraulic conductivity $\left(K_{0}\right)$ and sorptivity $\left(S_{0}\right)$ estimated with $\mathrm{C}_{\mathrm{DB}}$ were also compared to those obtained with $\mathrm{M}_{\mathrm{DB}}$. Finally, the cumulative infiltration curves measured with $\mathrm{C}_{\mathrm{DB}}$ and $\mathrm{M}_{\mathrm{DB}}$ were compared with the corresponding modelled function for the respective $K_{0}$ and $S_{0}$ values calculated with the $C L$ and DL models. The results show that, compared to $\mathrm{C}_{\mathrm{DB}}$ without a contact sand layer, $\mathrm{M}_{\mathrm{DB}}$ allows complete soil surface wetting even when non-smoothed soil surfaces are used. The $\mathrm{C}_{\mathrm{DB}}$, which yielded average $K_{0}$ values $18 \%$ lower than those estimated with $\mathrm{M}_{\mathrm{DB}}$, gave the highest values of standard error for the hydraulic parameters calculated. Further, the subjective method employed in the $\mathrm{C}_{\mathrm{DB}}$-DL technique, which requires the first points of the differential infiltration line corresponding to the sand layer to be manually removed, introduces additional uncertainties in estimating $S_{0}$ and $K_{0}$. Comparison between the modelled and measured infiltration curves demonstrates that the DL or CL methods applied to $\mathrm{M}_{\mathrm{DB}}$ gave excellent estimates of $S_{0}$ and $K_{0}$
\end{abstract}

Key words: Cumulative infiltration curve; Hydraulic conductivity; Sorptivity. 


\section{INTRODUCTION}

Over the last two decades tension disc infiltrometers (Perroux and White, 1988) have become very popular devices for in-situ estimates of soil surface hydraulic properties such as saturated and unsaturated hydraulic conductivity and sorptivity (White et al., 1992) and macropore flow contribution (Angulo-Jaramillo et al., 2000).

This instrument, commonly made of Plexiglass, consists of a disc base covered by a membrane, a graduated water-supply reservoir and a bubble tower with a moveable air-entry tube that imposes the pressure head at the cloth base (Perroux and White, 1988). The diameter of the disc base can range from the $25 \mathrm{~cm}$ proposed by Perroux and White (1988) to the $3.2 \mathrm{~cm}$ used by Madsen and Chandler (2007), which is useful when field research is remote, the water access is limited or a microtopography study is required. Soil hydraulic properties are commonly calculated from the cumulative water-infiltration curves, which are measured from the drop in the water level of the reservoir tower. Correct measurements of the infiltration curve require the membrane of the disc base to be completely in contact with the soil surface. To achieve this contact, Perroux and White (1988) recommended trimming any vegetation within the sample to ground level and covering the soil with a material that had a greater hydraulic conductivity than the soil and an air-entry value less than the minimum pressure head to be applied. The influence of the contact material on the disc infiltrometer measurements has been fairly extensively.studied. Reynolds and Zebchuk (1996) demonstrated that the thickness of the contact layer may have a significant influence on both the soil surface and membrane disc pressure heads. According to Reynolds (2006), the contact sand layer introduces an offset between the pressure head set on the bubble tower and the pressure head applied to the soil surface, which has varying impacts on relationships describing near-saturated hydraulic properties. The amount of overestimate and underestimate increases with increasing offset and should be 
corrected using a form of Darcy's law to prevent the introduction of systematic biases in infiltration results (Reynolds, 2006). Everts and Kanwar (1993) observed in several field experiments that measurements with a ponded infiltrometer taken at the same place and pressure head were one order of magnitude higher than those obtained with a disc infiltrometer placed on a 20 -mm layer of sand. More recently, Schwärzel and Punzel (2007) observed that saturated hydraulic conductivities measured with a disc infiltrometer placed on a sand contact layer were 10 times smaller than the corresponding values measured by a hood infiltrometer. These authors attributed these differences to smearing, sealing, and clogging of pores, which led to additional flow impedances in the soil surface layer. These results, however, disagree to those obtained by Reynolds (2008), who found that if the contact sand layer has the correct hydraulic properties and is placed correctly, it cannot decrease infiltration rates or smear, seal or clog soil macropores. Wetting of contact material may be another source of error in disc infiltrometer measurements. Close et al. (1998) showed that a non-uniform wetting of the contact material at the membrane interface resulted in differences in infiltration rates. Despite all these limitations, Minasny and McBratney (2000) concluded that contact sand was recommended because otherwise the poor contact between the disc base and the soil surface makes the absolute rate of infiltration considerably lower.

Soil hydraulic properties can be calculated from an analysis of the steady-state or transient water flows. Steady-state flow theory, which is based on the simple Wooding equation (1968), has been widely used and compared during the last few decades. However, the assumption of homogeneous isotropic soil with uniform initial water content required by the Wooding equation (1968), together with the length of time needed to achieve the steady-state water flow, restricts its use to field applications (Vandervaere et al., 2000). Determination of soil hydraulic properties from transient water flow analysis, which means shorter experiments and smaller sampled volumes of soil, is obviously in better agreement with assumptions of homogeneity and initial water uniformity 
(Angulo-Jaramillo et al., 2000). On the basis of previous work by Turner and Parlange (1974) and Smettem et al. (1994), Haverkamp et al. (1994) proposed a simple, physically based expression valid for short to medium time and very useful for estimating soil hydraulic properties from the transient water flow. Vandervaere et al. (2000) compared several methods of analysing the Haverkamp et al. (1994) equation for disc infiltrometer measurements and concluded that the linear fitting technique consisting in differentiating the cumulative infiltration data with respect to the square root of time allowed the best estimations of soil hydraulic properties. These authors suggested that direct nonlinear fitting on cumulative infiltration or infiltration flux was likely to lead to unacceptable errors, either because of difficulties in dealing with the non-uniqueness of the solution or the influence of the contact sand layer.

Despite all the above-described limitations of conventional disc infiltrometers, the disc infiltrometer is widely used at present owing to the rapid and portable nature of the technique and its easy in-situ applicability. The objective of this paper is to present an alternative design of infiltrometer disc base that allows complete contact with the soil surface without using a contact sand layer. The new disc base, which has a malleable membrane, was tested in structured soils with different forms of tillage management, and the soil hydraulic properties calculated were compared to those obtained with a conventional disc base that uses a contact sand layer between the soil surface and the disc.

\section{THEORY}

The three-dimensional cumulative infiltration per unit of area, $I(\mathrm{~mm})$, can be expressed as (Smettem et al., 1994)

$$
I_{3 D}=I_{1 D}+\frac{\gamma S^{2}}{R_{D}\left(\theta_{0}-\theta_{n}\right)}
$$


where the subscripts 3D and 1D refer to axisymmetric three-dimensional and one-dimensional processes respectively; $R_{D}(\mathrm{~m})$ is the radius of the disc; $\theta_{0}$ and $\theta_{n}$ are the final and initial volumetric water content $\left(\mathrm{m}^{3} \mathrm{~m}^{-3}\right)$, respectively; $S_{0}$ is the sorptivity $\left(\mathrm{m} \mathrm{s}^{-0.5}\right)$ for $\theta_{0}$; and $\gamma$ is the proportionality constant, the value of which can be approximated to 0.75 (Angulo-Jaramillo et al., 2000). For unsaturated conditions, the three-dimensional infiltration curve can be expressed in the quasi-exact analytical form (Haverkamp et al., 1994) as

$$
\begin{aligned}
& \frac{2\left(K_{0}-K_{n}\right)^{2}}{S_{0}^{2}} t=\frac{2}{1-\beta} \frac{K_{0}-K_{n}}{S_{0}^{2}} \cdot\left\{I_{3 D}-K_{n} t-\left[\gamma S_{0}^{2} / R_{D}\left(\theta_{0}-\theta_{n}\right)\right] t\right\} \\
& -\frac{1}{1-\beta} \cdot \ln \left\{\left\{\exp \left[2 \beta\left(K_{0}-K_{n}\right) / S_{0}^{2}\right]\left[I_{3 D}-K_{n} t-\left(\gamma S_{0}^{2} / R_{D}\left(\theta_{0}-\theta_{n}\right)\right) t\right]+\beta-1\right\}(\beta)^{-1}\right\}
\end{aligned}
$$

where $K_{0}$ and $K_{n}$ are the soil hydraulic conductivity values $\left(\mathrm{m} \mathrm{s}^{-1}\right)$ corresponding to $\theta_{0}$ and $\theta_{n}$, respectively, and $\beta$ is a shape constant that commonly takes an average value of 0.6 (AnguloJaramillo et al., 2000). In spite of its relative complexity, Eq. (2) is valid for the entire time range from $t=0$ to $t=\infty$. However, taking into account that infiltrometer experiments do not require very long time ranges of application, Haverkamp et al. (1994) established that, for short to medium time and assuming $K_{n} \rightarrow 0$, the 3D cumulative infiltration curve can be defined with the simplified but highly accurate equation

$$
I_{3 D}=S_{0} \sqrt{t}+\left[\frac{2-\beta}{3} K_{0}+\frac{\gamma S_{0}^{2}}{R_{D}\left(\theta_{n}-\theta_{0}\right)}\right] t
$$

The first term of the right-hand side corresponds to the vertical capillary flow and dominates the infiltration during its early stages. The second term corresponds to the gravity-driven vertical flow, and the third term represents the lateral capillary flow component (Angulo-Jaramillo et al., 2000).

Eq. (3) can be simplified to a two-term expression (Vandervaere et al., 2000) according to

$$
I=C_{1} \sqrt{t}+C_{2} t
$$


where

$$
C_{1}=S_{0}
$$

and

$$
C_{2}=\frac{2-\beta}{3} K_{0}+\frac{\gamma C_{1}^{2}}{R_{D}\left(\theta_{n}-\theta_{0}\right)}
$$

Several methods have been developed to infer $S_{0}$ and $K_{0}$ values from $C_{1}$ and $C_{2}$. Smiles and Knight (1976) proposed a linear fitting procedure [“cumulative linearization" (CL)] by dividing both sides of Eq. (4) by $\sqrt{t}$, giving

$$
\frac{I}{\sqrt{t}}=C_{1}+C_{2} \sqrt{t}
$$

and then plotting $\frac{I}{\sqrt{t}}$ as a function of $\sqrt{t}$.

More recently, Vandervaere et al. (2000) proposed an alternative linear fitting technique ["differentiated linearization" (DL)] that consists in differentiating the cumulative infiltration data with respect to the square root of time,

$$
\frac{d I}{d \sqrt{t}}=C_{1}+2 C_{2} \sqrt{t}
$$

and next plotting the $\frac{d I}{d \sqrt{t}}$ term as a function of $\sqrt{t}$. In these two models (Eqs. 7 and 8 ), $C_{l}$ is the intercept and $C_{2}$ the slope of the corresponding regression lines.

Vandervaere et al. (2000) analysed these two linear fitting techniques for conventional disc infiltrometer measurements that use a contact sand layer, and concluded that the DL technique (Eq. 8) was the only method that allowed visual monitoring of the validity and range of applicability of the two-term equation. According to these authors, this technique was good for revealing and 
eliminating, at the beginning of experiments, the influence of a sand contact layer, which may have negative effects on parameter estimations when not taken into account.

\section{MATERIAL AND METHODS}

\subsection{Disc infiltrometer design}

A modified Perroux and White (1988) compact tension disc infiltrometer was used. This is made of acrylic and consists of a disc base jointed to a water supply reservoir $(60 \mathrm{~cm}$ high and $3.4 \mathrm{~cm}$ internal diameter, i.d.) and a bubble tower (12 cm high and $3.4 \mathrm{~cm}$ i.d.) with a moveable air-entry tube that imposes the pressure head of the water at the cloth base. The air inlet in the disc base was made at $0.5 \mathrm{~cm}$ height from the soil surface. A \pm 0.5 psi differential pressure transducer (PT) (Microswitch, Honeywell), connected to a datalogger (CR1000, Campbell Scientist Inc.), was installed at the bottom of the water-supply reservoir (Casey and Derby, 2002). Two different 10-cmdiameter discs, with an inner conical wall that allows the bubbles to be driven from the disc base to the reservoir tower, were used. The first infiltrometer plate consisted of a conventional disc $\left(\mathrm{C}_{\mathrm{DB}}\right)$. This had a metallic grid (with 1-cm square holes) glued at the base which, in turn, was covered with a tightened nylon cloth of $20-\mu \mathrm{m}$ mesh (air-entry value of about $-7.5 \mathrm{kPa}$ ). The alternative disc base $\left(\mathrm{M}_{\mathrm{DB}}\right)$ was similar to $\mathrm{C}_{\mathrm{DB}}$, but covered with a loosened, malleable nylon cloth of $20-\mu \mathrm{m}$ mesh filled with $100 \mathrm{~g}$ of coarse sand (1-1.5 mm grain size) (Fig. 1) (0.5-cm-thick layer, approximately). This design allows the loosened nylon cloth to adapt to a relatively smooth area when the infiltrometer is placed on the soil surface.

\subsection{Infiltration measurements}

The two disc bases, which were previously calibrated in laboratory according to Reynolds (2008) procedure, were tested in a series of field experiments on structured soils under different forms of 
tillage management. The site is located at the dryland research farm of the Estación Experimental de Aula Dei (CSIC) in the province of Zaragoza (latitude 418440N; longitude 08460W; altitude $270 \mathrm{~m}$ ). The climate is semiarid with an average annual precipitation of $390 \mathrm{~mm}$ and an average annual air temperature of $14.5^{\circ} \mathrm{C}$. The soil at the research site is a loam (fine-loamy, mixed thermic Xerollic Calciorthid) according to the USDA soil classification (Soil Survey Staff, 1975). The particle size distribution for the plough layer $(0-40 \mathrm{~cm})$ averages $25 \%$ clay, $47 \%$ silt and $28 \%$ sand (López et al., 1996).

The study was conducted on a large block of plots, which were set up on a nearly level area (slope 0-2\%) of land in 1991 within a long-term conservation tillage experiment initiated in 1989. The field was in continuous winter barley (Hordeum vulgare L.) cropping, and the study was conducted three months after harvest, prior to any primary tillage operations.

Three different tillage treatments were examined: conventional tillage $(\mathrm{CT})$, reduced tillage $(\mathrm{RT})$ and no-tillage (NT). The CT treatment consisted of mouldboard ploughing of fallow plots to a depth of $30-40 \mathrm{~cm}$ in late winter or early spring, followed by secondary tillage with a sweep cultivator to a depth of $10-15 \mathrm{~cm}$ in late spring. In the RT treatment, the primary tillage was chisel ploughing to a depth of 25-30 cm (non-inverting action), followed by a pass of the sweep cultivator in late spring. NT used exclusively herbicides (glyphosate) for weed control throughout the fallow season. The tillage treatments were arranged in a complete block design. The size of the basic plot was $33.5 \mathrm{~m} \mathrm{x}$ $10 \mathrm{~m}$, with a separation of $1 \mathrm{~m}$ between plots. One infiltration measurement with the conventional and malleable discs was performed per plot. A total of 3 replications were made for each tillage management and type of disc base.

The soil dry bulk density $\left(\rho_{b}\right)$ was determined by the core method with core dimensions of $50 \mathrm{~mm}$ diameter and $50 \mathrm{~mm}$ height. The core samples were taken the same day and near the measurement 
locations for the hydraulic properties. This sampling also allowed us to determine the prior volumetric water content needed to calculate the soil hydraulic properties.

The soil hydraulic properties were characterised at each observation point using the tension disc infiltrometer described above. Infiltration measurements were taken on areas cleared of surface crust, large clods and crop residue. For the conventional disc $\left(\mathrm{C}_{\mathrm{DB}}\right)$ a thin layer $(<1 \mathrm{~cm}$ thick $)$ of commercial sand (80-160 $\mu \mathrm{m}$ grain size and an air-entry value between -1 and $-1.5 \mathrm{kPa}$ ), with the same diameter as the disc base, was poured onto the soil surface. The infiltrometer with a malleable membrane $\left(\mathrm{M}_{\mathrm{DB}}\right)$ was directly placed on the soil surface. The pressure head $\left(\psi_{0}\right)$ in the bubble tower was $-0.5 \mathrm{~cm}$. The actual pressure head on the soil surface, $\psi_{s}(\mathrm{~mm})$, was recalculated according to (Reynolds and Zebchuk, 1996; Reynolds, 2006)

$$
\psi_{s}=\psi_{0}+\left[\frac{K_{C S} T_{C S}-q\left(\psi_{0}\right) T_{C S}}{K_{C S}}\right]
$$

where $q\left(\psi_{0}\right)\left(\mathrm{mm} \mathrm{s}^{-1}\right)$ is the measured flux density out of the tension infiltrometer at a set pressure head, $\psi_{0}(\mathrm{~mm}), T_{C S}(\mathrm{~mm})$ is the thickness of the contact sand layer, and $K_{C S}\left(\mathrm{~mm} \mathrm{~s}^{-1}\right)$ is the saturated hydraulic conductivity of the contact sand layer. In our study, the average $K_{C S}$ value estimated from several sand column laboratory experiments was $0.125 \mathrm{~mm} \mathrm{~s}^{-1}$. The scanning time interval for the PTs was 5 seconds, and the infiltration measurements lasted up to 8-10 $\mathrm{min}$ in total. The cumulative water infiltration was measured from the drop in water level of the reservoir tower. At the end of infiltration, a wet soil sample was also taken to estimate the final gravimetric water content (W). The final volumetric water content needed to calculate the soil hydraulic properties was calculated as the product of $\mathrm{W}$ and $\rho_{b}$.

The comparison between how well the $\mathrm{C}_{\mathrm{DB}}$ and $\mathrm{M}_{\mathrm{DB}}$ plates estimate the soil hydraulic properties, which were made separately within each tillage system, took place in three steps. Once the cumulative infiltration curves had been measured, the coefficient of determination $\left(\mathrm{R}^{2}\right)$ and the 
significance $(p)$ of the linearized regression models calculated by the DL (Eq. 8) method for the $\mathrm{C}_{\mathrm{DB}}$ and $\mathrm{M}_{\mathrm{DB}}$ plates were contrasted with the corresponding statistical parameters obtained with the CL (Eq. 7) model applied to the $\mathrm{M}_{\mathrm{DB}}$ measurements. Similarly, the $S_{0}$ (Eq. 5) and $K_{0}$ (Eq. 6) values calculated by $\mathrm{DL}$ for the cumulative infiltration curves measured with both the $\mathrm{C}_{\mathrm{DB}}$ and $\mathrm{M}_{\mathrm{DB}}$ plates were compared with the corresponding hydraulic parameters estimated by $C L$ applied to the $M_{D B}$ data. Finally, the cumulative infiltration curves measured with the $C_{D B}$ and $M_{D B}$ plates were compared with the corresponding 3D modelled function (Eq. 2) (Latorre, 2011) for the respective $K_{0}$ and $S_{0}$ values calculated by the CL and DL methods.

\section{RESULTS AND DISCUSSION}

The average increase of the pressure head in the base disc due to the bubble system, calculated according to Reynolds (2008) procedure, was about $0.1 \mathrm{~cm}$. It means that the initial pressure head applied to the base of the disc infiltrometers was about $-0.4 \mathrm{~cm}$. According to Darcy's law, the increase in pressure head at the soil surface due to the head losses caused by the water flowing through the $0.5-\mathrm{cm}$ coarse sand layer in the $\mathrm{M}_{\mathrm{DB}}\left(\Delta \psi_{s}=\psi_{s}-\psi_{0}\right)$ (with an estimated saturated hydraulic conductivity of $6.710^{-4} \mathrm{~m} \mathrm{~s}^{-1}$ ) and calculated for the maximal water flow measured at the beginning of the infiltration experiments (i.e. $1.510^{-6} \mathrm{~m}^{3} \mathrm{~s}^{-1}$ ) was lower than $1.4 \mathrm{~mm}$ (Fig. 2). This $\Delta \psi_{s}$ value, that for the most extreme scenario represents an effective pressure head decreasing of about $28 \%$, should not be ignored since small changes in effective pressures may produce substantial changes in infiltration rates and calculated soil hydraulic properties, especially in macroporous soils (Reynolds, 2006). A more significant effect of the contact sand layer on the effective pressure head $\left(\psi_{s}\right)$ was observed in the $\mathrm{C}_{\mathrm{DB}}$ infiltrometer. In this case, the $\Delta \psi_{s}$ (Eq. 9) during the first infiltration steps (up to 20 seconds) had a maximal value of $4 \mathrm{~mm}$ (Fig. 2). This value, which increases $80 \%$ the effective pressure head, should be attributed to the fine sand placed between the soil surface and the 
disc base. Although these effects may be minimized by using coarser sand, the lower air-entry values of the coarser contact layer would limit the range of pressure heads to be applied during infiltration measurements. These results show an additional limitation of the $\mathrm{C}_{\mathrm{BD}}$ infiltrometer to estimate the soil hydraulic properties from the transient flow data. The average value and the standard error of the bulk density measured for CT, RT and NT tillage management were $1.29,1.21$ and $1.42 \mathrm{~g} \mathrm{~cm}^{-3}$, and $0.12,0.08$ and $0.03 \mathrm{~g} \mathrm{~cm}^{-3}$, respectively. The average value and the standard error of initial and final water contents measured in the upper soil layer were $0.04 \mathrm{~m}^{3} \mathrm{~m}^{-3}$ and $0.418 \mathrm{~m}^{3} \mathrm{~m}^{-3}$, and 0.007 and $0.029 \mathrm{~m}^{3} \mathrm{~m}^{-3}$, respectively.

The soil surface at the end of the infiltration measurement after removing the $C_{D B}$ shows that the rigid base of the conventional disc cannot completely wet the soil surface when no sand contact layer is used (Fig. 3a). In contrast, both the $\mathrm{C}_{\mathrm{DB}}$ with a sand contact layer and $\mathrm{M}_{\mathrm{DB}}$ allow complete soil surface wetting even when non-smoothed soil surfaces are tested (Fig. 3b). These visual observations confirm that the $\mathrm{M}_{\mathrm{DB}}$ design may be a good alternative to the conventional disc, which commonly uses a sand layer to ensure the contact between the disc base and the soil surface. However, some care should taken when analysing these results since aggregate slaking/dispersion observed under the $\mathrm{C}_{\mathrm{DB}}$ without contact sand (Fig. 2a) and the $\mathrm{M}_{\mathrm{DB}}$ (Fig. 2c) may affect the infiltration rates and the calculated soil hydraulic properties. Soil aggregates may be less susceptible to slaking/dispersion if they were "protected" from the disc infiltrometer membrane by a contact sand layer (Fig. 2b).

Comparison between the cumulative infiltration curves measured with $\mathrm{C}_{\mathrm{DB}}$ and $\mathrm{M}_{\mathrm{DB}}$ in a soil under CT and NT tillage managements allows the effect of the sand layer on the infiltration curve to be distinguished (Fig. 4). Compared to $\mathrm{M}_{\mathrm{DB}}$, the cumulative infiltration curve obtained with $\mathrm{C}_{\mathrm{DB}}$ shows a jump at the beginning of the experiment due to the additional water stored in the contact sand layer. This jump, however, vanishes in the $\mathrm{M}_{\mathrm{DB}}$ cumulative infiltration curve, where the malleable disc base makes direct contact with the soil surface. 
Figure 5 shows two examples of the DL and CL models used to estimate $C_{1}$ and $C_{2}$ (Eq. 4 ) for the cumulative infiltration curves of Fig. 4 measured with $\mathrm{C}_{\mathrm{DB}}$ and $\mathrm{M}_{\mathrm{DB}}$. As described by Vandervaere et al. (2000), the DL method applied to the cumulative infiltration curve measured with $\mathrm{C}_{\mathrm{DB}}$ makes it possible to reveal and eliminate, at the beginning of experiments, the influence of the sand contact layer on the infiltration curve (Fig. 5a). The same DL model applied to the cumulative infiltration curve measured with $\mathrm{M}_{\mathrm{DB}}$ shows that the absence of the sand contact layer makes it possible to include in the analysis the first times of the infiltration curve (Fig. 5b). Excellent linear behaviours were found in the CL analysis for the cumulative infiltration curve measured with $\mathrm{M}_{\mathrm{DB}}$ (Fig. 5c). Statistical analysis of the regression lines calculated for the cumulative infiltration curves measured with the different discs shows that the DL model applied to the infiltration curves obtained with $\mathrm{M}_{\mathrm{DB}}$ and $\mathrm{C}_{\mathrm{DB}}$ has worse $\mathrm{R}^{2}$ and significance $(p)$ values for the linearized regression lines in comparison with the $\mathrm{M}_{\mathrm{DB}}-\mathrm{CL}$ method (Table 1). This is due to the discontinuous bubbling in the water-supply reservoir, which gives the cumulative infiltration curve a kind of smoothed stair-shape (MoretFernández et al. 2011). This results in highly "noised" differentiated regression lines (Fig. 5a and b), which decrease the accuracy in estimating the $C_{1}$ and $C_{2}$ parameters. In these cases, and in order to increase to accuracy of the regression lines analysis, points plotted outside from the lines defining the $99 \%$ of confidence intervals were removed. Statistical analysis of the DL model applied to the two disc bases shows that, on average, the $\mathrm{M}_{\mathrm{DB}}$ presents better $\mathrm{R}^{2}$ and $p$ values than those obtained with $\mathrm{C}_{\mathrm{DB}}$ (Table 1). The worse results observed with $\mathrm{C}_{\mathrm{DB}}$ may be attributed to the contact sand layer, which can create small interferences in the measurement of the cumulative infiltration curve. For instance, an excess or non-uniform distribution of sand around the disc may promote irregular sand wetting (Close et al., 1998), which can result in higher noise in the DL analysis. These distortions due to the contact sand layer resulted in the $S_{0}$ and $K_{0}$ values calculated with $\mathrm{C}_{\mathrm{DB}}-\mathrm{DL}$ presenting, on average, the highest standard errors (Table 2). On average, the $K_{0}$ value estimated with $\mathrm{M}_{\mathrm{DB}}$ was $18 \%$ 
higher than the corresponding hydraulic conductivities calculated with $\mathrm{C}_{\mathrm{DB}}$. These differences may be attributed, as Schwärzel and Punzel (2007) reported, to the contact sand layer, which smears, seals, and clogs some soil macropores, decreasing the soil water infiltration rates. Alternatively, this higher $K_{0}$ under $\mathrm{M}_{\mathrm{DB}}$ could be explained by the deformation of the $\mathrm{M}_{\mathrm{DB}}$ membrane upon placement on the soil surface. This could produce a momentary "pulse" (increase) in the $\psi_{s}$ value, which may introduce complicating hysteresis effects into both the measured cumulative infiltration curve and the resulting $K_{0}$ and $S_{0}$ calculations. Such a pulse could explain the $18 \%$ greater $K_{0}$ from the $\mathrm{M}_{\mathrm{DB}}$ relative to the $\mathrm{C}_{\mathrm{DB}}$.

Excellent fittings, with small RMSE values (Table 2), were observed between the cumulative infiltration curves measured with $\mathrm{M}_{\mathrm{DB}}$ and the corresponding modelled curves for the $S_{0}$ and $K_{0}$ parameters estimated by both CL and DL techniques (Fig. 6). In this case, a general overlapping was observed between the measured and modelled curves. Although no statistical analysis for the comparison between the modelled and measured $\mathrm{C}_{\mathrm{DB}}$ infiltration curves was possible, in general parallel modelled vs. measured infiltration curves (Fig. 6a) were obtained.

\section{CONCLUSIONS}

This paper presents an alternative design of infiltrometer disc base with a malleable membrane $\left(\mathrm{M}_{\mathrm{DB}}\right)$ that allows excellent contact with the soil surface without using a contact sand layer. The new disc was tested in a structured soil under different tillage treatments, and the calculated soil hydraulic properties were compared with those obtained with a conventional disc base $\left(\mathrm{C}_{\mathrm{DB}}\right)$, which uses a contact sand layer between the soil and the infiltrometer. Although the three methods described here $\left(\mathrm{C}_{\mathrm{DB}}-\mathrm{DL}, \mathrm{M}_{\mathrm{DB}}-\mathrm{DL}\right.$ and $\left.\mathrm{M}_{\mathrm{DB}}-\mathrm{CL}\right)$ to estimate soil hydraulic properties from the analysis of the cumulative infiltration curve give realistic values of $S_{0}$ and $K_{0}$, the $\mathrm{C}_{\mathrm{DB}}-\mathrm{DL}$ technique proved to be the most inaccurate procedure (with the highest standard errors) for estimating soil hydraulic 
properties. The field applicability of the $\mathrm{C}_{\mathrm{DB}}$ infiltrometer, which requires a contact sand layer to be placed between the soil and the disc base, proved to be more time-consuming than the alternative $\mathrm{M}_{\mathrm{DB}}$ design. Moreover, the subjective procedure required by the $\mathrm{C}_{\mathrm{DB}}-\mathrm{DL}$ method, in which the first points of the differentiated infiltration curve corresponding to the sand layer have to be manually removed, introduces additional uncertainties in the estimations of the soil hydraulic parameters.

The main advantages of $\mathrm{M}_{\mathrm{DB}}$ compared to $\mathrm{C}_{\mathrm{DB}}$ can be summarized as:

1.- Complete soil surface wetting without placing a contact sand layer, even when relatively unsmoothed soil surfaces were used.

2.- Faster field applicability.

3.- Elimination of the interferences caused by the sand layer in the analysis of the cumulative infiltration curve.

4.- Analysis of the cumulative infiltration curve using either the cumulative linearization or differentiated linearization models.

5.- More accurate estimates of $S_{0}$ and $K_{0}$ from the analysis of the measured cumulative infiltration curves.

6.- Direct comparison of the measured infiltration curve with the modelled three-dimensional function, which makes it possible to ensure that the hydraulic parameters have been correctly approached.

Despite all these advantages, further efforts should be done to study:

i) The potential applicability of $\mathrm{M}_{\mathrm{DB}}$ in soil surface with abrupt changes in elevation (e.g. protruding aggregates or stones, steep-walled 3 depressions, etc).

ii) The hysteresis effects produced by the deformation of the $M_{D B}$ membrane upon placement on the soil surface. This problem could be partially solved by incorporating a manometer at the base of 
the disc, which checked the actual pressure head. Parallel this may be corrected by using a combined $\mathrm{M}_{\mathrm{DB}}-\mathrm{CL}$ and $\mathrm{M}_{\mathrm{DB}}-\mathrm{DL}$ analysis.

iii) The feasibility of $\mathrm{M}_{\mathrm{DB}}$ to measure the soil hydraulic properties under unsaturated conditions: if applied pressure heads are lower than the air-entry value for the pores created between the soil surface and the malleable membrane, possible contact problems between soil surface and the base disc may be achieved.

iv) The effect of aggregate slaking/dispersion due the fast soil surface wetting under the malleable membrane (Fig. 2c) on the estimate of the soil hydraulic properties.

\section{Acknowledgements}

This research was supported by the Ministerio de Ciencia e Innovación of Spain (grant AGL201022050-C03-02) and by the Aragón regional government and La Caixa (Grants: GA-LC020/2010). The authors are grateful to Valero Perez for his help in various technical aspects of this study.

\section{REFERENCES}

Angulo-Jaramillo R, Vandervaere JP, Roulier S, Thony JL, Gaudet JP, Vauclin, M. 2000. Field measurement of soil surface hydraulic properties by disc and ring infiltrometers. A review and recent developments. Soil Tillage Research 55: 1-29.

Casey FXM, Derby NE. 2002. Improved design for an automated tension infiltrometer. Soil Science Society of America Journal 66: 64-67.

Close KR, Frasier G, Dunn GH, Loftis JC. 1998. Tension infiltrometer contact interface evaluation by use of a potassium iodide tracer. Transactions ASAE 41:995-1004.

Everts CJ, Kanwar RS. 1993. Interpreting tension-infiltrometer data for quantifying soil macropores: Some practical considerations. Transactions ASAE 36: 423-428. 
Haverkamp R, Ross PJ, Smettem KRJ, Parlange JY. 1994. Three dimensional analysis of infiltration from the disc infiltrometer. Part 2. Physically based infiltration equation. Water Resources Research 30: 2931-2935.

Latorre B. 2011. CIC - Plotting application for 1D and 3D soil water cumulative infiltration curves. https://apps.eead.csic.es/EEAD/apps/sueloyagua/fslc/infiltration/index.html.

López MV, Arrúe JL, Sánchez-Girón V. 1996. A comparison between seasonal changes in soil water storage and penetration resistance under conventional and conservation tillage systems in Aragón. Soil Tillage Research 37: 251-271.

Madsen, M.D., Chandler, D.G. 2007. Automation and use of mini disk infiltrometers. Soil Science Society of America Journal 71: 1469-1472.

Minasny B, McBratney AB. 2000. Estimation of sorptivity from disc-permeameter measurements Geoderma 95: 305-324.

Moret-Fernández , D., González, C. , Latorre, B. 2011. New design of microflowmeter-tension disc infiltrometer: I. Measurement of the transient infiltration rate. Journal of Hydrology (under review).

Perroux KM, White I. 1988. Designs for disc permeameters. Soil Science Society of America Journal 52: $1205-1215$.

Reynolds WD. 2006. Tension infiltrometer measurements implications of pressure head offset due to contact sand. Vadose Zone Jounral 5: 1287-1292.

Reynolds WD, Zebchuk WD. 1996. Use of contact material in tension infiltrometer measurements. Soil Technology 9:141-159.

Reynolds, W.D. 2006. Tension infiltrometer measurements: implications of pressure head offset due to contact sand. Vadose Zone Journal 5: 1287-1292. 
Reynolds, W.D. 2008. Unsaturated hydraulic properties: field tension infiltrometer. Chap. 82 in M.R.

Carter and E.G. Gregorich (ed.) Soil Sampling and Methods of Analysis, 2nd ed. Canadian Society of Soil Science, CRC Press, Boca Raton, FL.

Schwärzel K, Punzel J. 2007. Hood infiltrometer-A new type of tension infiltrometer. Soil Science Society of America Journal 71: 1438-1447.

Smettem KRJ, Parlange JY, Ross PJ, Haverkamp R. 1994. Three-dimensional analysis of infiltration from the disc infiltrometer. Part 1. A capillary-based theory. Water Resources Research 30: 2925-2929.

Smiles DE, Knight JH. 1976. A note on the use of the Philip infiltration equation. Australian Journal of Soil Research 14: 103-108.

Soil Survey Staff. 1975. Soil taxonomy: a basic system of soil classification for making and interpreting soil surveys. USDASCS Agric. Handbook 436. US Govt. Print. Office, Washington, DC.

Turner NC, Parlange JY. 1974. Lateral movement at the periphery of a one-dimensional flow of water. Soil Science 118: 70-77.

Vandervaere JP, Vauclin M, Elrick DE. 2000. Transient Flow from Tension Infiltrometers. Part 1. The two-parameter Equation. Soil Science Society of America Journal 64: 1263-1272.

White I, Sully MJ, Perroux KM. 1992. Measurement of surface-soil hydraulic properties: disc permeameters, tension infiltrometers and other techniques. In: Topp, G.C., et al. (Eds.), Advances in Measurement of Soil Physical Properties: Bringing Theory into Practice. Soil Sci.

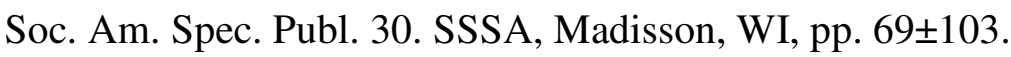

Wooding RA. 1968. Steady infiltration from a shallow circular pond. Water Resources Research 4: 1259-1273. 


\title{
FIGURE CAPTIONS
}

Figure 1. Details of the malleable disc base.

Figure 2. Final $\left(\psi_{s}\right)$ and the increase in pressure head $\left(\Delta \psi_{s}\right)$ at the soil surface due to the head losses caused by the inner sand in the $\mathrm{M}_{\mathrm{DB}}$ and the contact sand layer in $\mathrm{C}_{\mathrm{DB}}$.

Figure 3. Soil surface at the end of an infiltration experiment after removing the conventional plate (a) without and (b) with a contact sand layer, and (c) after removing the malleable disc base.

\author{
Figure 4. Cumulative infiltration curves for the corresponding third and second replications in the (a) \\ conventional and (b) no-tillage treatments measured with the conventional (white circles) \\ and malleable (grey circles) discs, respectively.
}

Figure 5. Differentiated linearization (DL) model applied to the cumulative infiltration curves of Fig. 4 measured with the (a) conventional and (b) malleable disc bases; and (c) the cumulative linearization (CL) method applied to the cumulative infiltration curves of Fig. 4 measured with a malleable disc base. White and grey circles in Fig. 5a denote the section of the linear fitting curve corresponding to the contact sand layer and surface soil, respectively. Crosses indicate removed points.

Figure 6. Comparison between the $3 \mathrm{D}$ modelled and measured cumulative infiltration curves recorded on the soil surface under conventional tillage and no-tillage management (Fig. 4) with (a) the conventional and (b) malleable discs, respectively. 